\title{
Reflections of a president
}

B elfast Spring Meeting 26 May 2001, listening to doctor, now professor, George Kinghorn's masterful presidential address, and reality struck. The adrenaline rush accompanied by tachycardia and perspiration was laid to rest by his few words of advice ... that each president brings their own individuality to the role, that I would be able to do the job, and I must do it in my own way. But I should always be aware that the role of president is to represent the members of the organisation and the specialty across the United Kingdom.

The president's job has to be viewed in the context of the role of the organisation. As the Medical Society for the Study of Venereal Diseases (MSSVD) president I viewed the two years as an opportunity to build on the professional, scientific, and educational initiatives and ensure their delivery. Collaborating with the Association of Genitourinary Medicine to influence national and local policy agenda, and to bring the two organisations together under one structure without losing the unique contribution of each, was of equal importance. I never doubted the need for merger. No one anticipated the barrage of change starting with the publication of the National Sexual Health and HIV Strategy in 2001, my first year as MSSVD president, and escalating through the past four years. The benefit of utilising all the talents and having a unified approach from one organisation within the plethora of other "sexual health" stakeholders has become manifest over the past year.

The challenge of being the inaugural president of the British Association for Sexual Health and HIV (BASHH) was still daunting despite the invaluable experience as MSSVD president. BASHH exists because of its membership and as a charitable institution for the benefit of the public. BASHH must have the authority to influence health and healthcare policies, to work in collaboration with other major stakeholders involved in health care including specifically sexual health, and to provide leadership for its membership. This requires the commitment and involvement of all members of BASHH individually and collectively. BASHH needed to find its place within the rapidly changing environment, including changes in education, service delivery, and workforce alongside sociocultural changes. My role as president was to look inwards to the structure, function, and performance of the organisation and to look outwards to the political context and how to influence the external environment. BASHH cannot have influence unless it earns the respect of those we wish to influence to better serve the needs of our patients and the public. I remain convinced that our specialist services, which encompass an open access primary care function through to specialist tertiary services, including complex HIV care, are crucial. For the most part our services deliver patient centred care, address not just illness but prevention, and represent good value for money. This is not saying that we are "protectionist," complacent, and resistant to change. We must examine what we are doing, how we can do it better, and how we can involve and support others to improve their performance in managing sexual health issues.

However, my passionate conviction in the value of our services, shared by others, has given me the energy and commitment to persevere and drive forward initiatives that I thought would benefit our patients and earn respect for us as professionals and patient advocates.

For the past two years there has been a bedding down process of the internal infrastructure of the organisation, clarifying the purpose and remit of the different committees and communications between them, and ensuring that in the more complex organisation, charitable governance and financial probity are maintained. This is not straightforward and has led to frustrations in some quarters but we have been on a learning curve. Overall, we have succeeded in expanding our activities and ensuring transparency.

A major challenge for all of us has been raising the profile of $\mathrm{BASHH}$ and reflecting the difficulties of what is happening at the sharp end of service delivery to influence policy makers through the Department of Health sexual health team and directly with ministers of state. I have seen that to do this in partnership with other organisations is likely to be more productive-if professionals and patient advocacy groups appear to be divided then our chance to influence is minimal. We may not always agree, but a mutual understanding of where our opinions differ, with opportunities to discuss and negotiate, are vital.

To be a successful president it is important to realise that the presidency is part of a continuum. I view one of my greatest successes as having passed on a flourishing organisation that is fit for the future. The membership has grown by $18 \%$ in two years, with the greatest increase in non-medical categories. Despite increased expenditure, this has been more than matched by income from the very successful meetings and courses run by BASHH. The joint Spring meetings with the American Sexually Transmitted Diseases Association (ASTDA) in Bath in 2004 and the British HIV Association (BHIVA) in Dublin in 2005 were highlights, with excellent science, social activities, and collaborative atmosphere. The formalisation of media and PR activities has resulted in much greater recognition of BASHH as a stakeholder, through engagement of talents of several members rather than one or two individuals. Professional advice has ensured that we have become more proactive than reactive. My desire to increase the recognition of microbiology as an important part of our work and to facilitate multidisciplinary working within BASHH has progressed. Educational activities and development of a competency based approach to support delivery of quality sexual health wherever provided has been a crusade that will continue. All these have not been just my effort but have required the synergistic work of officers, chairs of committees, and active members of the society. To help deliver various initiatives, I have sought those people with a range of skills that are complementary to the president and officers. I have tried to ensure that where I recognise weakness I have selected others who have the necessary strengths. This "kitchen cabinet" has been a great support, offering sound advice and constructive criticism.

In medicine, the skills and attitudes required to build up a department and influence other organisations with which we work are somewhat different from those for direct patient care, although looking after patients while bringing credibility also ensures humility. Debating skills, public speaking, and thespian attributes are definitely advantageous. Dancing and singing 
come a poor second! It is possible to compensate for other defects. Having noted how easily one can be overlooked when surrounded by tall men in suits, I adopted the strategy of wearing bright clothes to be noticed. I wanted to bring a professional approach to our activities in the public arena. Preparation, anticipation of what might go wrong with contingency plans, attention to detail, and awareness of others' wellbeing are key. Others judge the president and BASHH on our performance. A business-like approach, making our achievements known, and being respectful of and appreciating the contributions of others all play a part in that judgment. Introducing the president's chain of office, making more of the endowment of honorary fellowships and, in the future, the giving of a BASHH lifetime achievement award are part of my legacy.
It was a great honour to be elected as the first president of BASHH and a great privilege to serve the new association, to represent the specialty, and to be in a position to exert influence wherever there is an opportunity to do so. I have had tremendous support throughout the past two years from the grass root membership to the older statesmen. Being president has been pleasurable, challenging, and a journey of personal discovery. But being president is not about oneself. It is not about being popular. It is about a hard job to be done for members to ultimately benefit patients and the public. It can be lonely. It is demanding, time consuming, and requires resilience and an ability to manage one's physical and psychological resources. It has required me to invest my intellectual, professional, and personal resource, particularly to other organisations and to individuals within them. The integrity of the president, the respect and trust invested in future individuals in their role as president, are paramount to the future success of BASHH. But as president, one has the freedom to bring one's own personality to the job and do it in one's own way. I gave it my best shot!

\section{ACKNOWLEDGEMENTS}

I would like to acknowledge Dame Carol Black who shared her views of the presidency of RCP with me, from which I derived inspiration.

\section{Angela J Robinson}

Mortimer Market Centre, off Capper Street London, UK; arobinson@gum.ucl.ac.uk

Angela J Robinson is the immediate past president of BASHH. The new president is Simon Barton. 